\title{
Demand for Family Planning among Poor Women in Uganda: Analysis of the Uganda Demographic and Health Surveys
}

\author{
Allen Kabagenyi ( $\square$ allenka79@yahoo.com ) \\ Makerere University School of Statistics \\ Pamela Kakande \\ Uganda Bureau of Statistics \\ Vianney Owayezu \\ Ministry of Health Uganda
}

\section{Research}

Keywords: DHS, demand for family planning, poor women, Uganda

Posted Date: October 21st, 2020

DOI: https://doi.org/10.21203/rs.3.rs-39847/v2

License: (c) (i) This work is licensed under a Creative Commons Attribution 4.0 International License.

Read Full License 


\section{Abstract}

Background: Family planning is one of the major cost-effective interventions to improve maternal health, reduce maternal and child mortality, and prevent unplanned pregnancies, yet its use remains low in subSaharan Africa, especially among the poor. In Uganda, little is known about the factors influencing the demand for family planning among the poor. This study examines the determinants of demand for family planning among poor women in a low income country.

Methods: The study is based on data from the 2006, 2011, and 2016 Uganda Demographic and Health Surveys (UDHS). The analysis was carried using weighted samples of 2,238 in 2006, 2,164 in 2011, and 4,370 in 2016. Descriptive statistics, and binary logistic regressions presenting both the unadjusted and adjusted were used to examine the influence of different demographic, behavioral, and socioeconomic factors on poor women's demand for family planning.

Results: Our findings showed demand for family planning was $56 \%$ in $2006,60 \%$ in 2011 , and $65 \%$ in 2016 among women in the poorest and poorer household health quintiles who were married or in union. In all three surveys, women age 25-39 had higher odds of demand for family planning compared with women age 15-24 (AOR=1.5, 95\% $\mathrm{Cl}=1.1-1.9$ in 2006, $A O R=2.2,95 \% \mathrm{Cl}=1.7-2.7$ in 2011, $\mathrm{AOR}=1.7,95 \%$ $\mathrm{Cl}=1.5-2.0$ in 2016). Women with no education had lower odds of demand for family planning compared with those with secondary education ( $\mathrm{AOR}=0.4,95 \% \mathrm{Cl}=0.3-0.6$, pooled results). Also, in the $2011 \mathrm{UDHS}$, women who had heard about family planning on the radio had higher odds of demand ( $A O R=1.4,95 \%$ $\mathrm{Cl}=1.1-1.7$, pooled) for family planning compared with those who had not, and in the 2006 survey women who had discussed family planning at a health facility had higher odds of demand for family planning ( $A O R=1.0,95 \% \mathrm{Cl}=0.8-1.2)$ compared with women who had not done so.

Conclusions: Demand for family planning is influenced by a woman's age, educational attainment, religion, exposure to family planning messages on the radio, and discussion on family planning at a health facility. This study underscores the need for increased family planning counseling by health workers and more discussion about family planning at the health facility. The findings further suggest the need to provide increased adequate family planning services and information for the poor, uneducated, and rural women to meet the demand for family planning.

\section{Introduction}

Family planning is one of the major cost-effective interventions to reduce maternal and child mortality, yet its use remains low in sub-Saharan Africa $[1,2]$. The use of effective modern contraceptive methods has been linked to prevention of unplanned pregnancy and abortions, and reduction of repeat pregnancies, which are a great risk to the health of the mother [2, 3]. Globally, over 200 million women have an unmet need for family planning-that is, they would like to either space or limit their births, but are not using any method of contraception to achieve their fertility desires $[4,5]$ 
United Nations Sustainable Development Goal 3 (SDG 3) stipulates the need for joint efforts to ensure healthy lives and promote well-being for all people at all ages. In sub-Saharan Africa, unmet need for family planning has remained continually high and corresponding contraceptive prevalence is low [6]. It is evident that many women who wish to use contraceptive methods meet hindrances linked to access, misconceptions, and availability of the different methods [7, 8]. Moreover, the United Nations global goals further highlight the need for inclusive growth for all with an ambitious goal of "leaving no one behind" by supporting the neglected/ignored population subgroups.

The poor are classified among the vulnerable, excluded, and marginalized/discriminated population groups [9]. Furthermore, reducing unmet need has a significant effect on maternal and child health outcomes and helps women fulfill their fertility intentions $[8,10]$. There is no doubt that investment in family planning would yield great benefits and save costs related to maternal health care [11]. In many countries, the low level of use of modern contraception translates into high fertility levels, as in Uganda, which is one of the countries in the region with the highest fertility rates, at 5.4 children per woman [12, 13]. While the benefits of using contraception are known, given the nearly universal knowledge of family planning among women and men, prevalence of any contraceptive method use remains low in Uganda at only $35 \%$ among married women [14].

A review of the vulnerable groups depicts the poor being left behind, yet they are in great need of family planning services $[15,16]$. The poor have the lowest contraceptive prevalence among all population groups, especially in low-income countries. Findings on differential effects of household wealth status on modern contraceptive use and fertility among women in Malawi, for example, showed that the prevalence of ever use of modern contraceptives was significantly higher among women in the richest wealth quintile compared with the poorest, and the pattern was similar for current contraceptive users [15]. Similarly, over the years the Demographic and Health Surveys (DHS) have shown inequalities in the use of family planning methods between women in poor and rich households.

Notably, in the most recent DHS survey in Uganda, the total fertility rate (TFR) was highest in the lowest wealth quintile, at 7.1, and lowest in the highest wealth quintile, at 3.8. This is consistent with contraceptive prevalence being lowest in the poorest wealth quintile, at $25 \%$, and highest in the richest quintile, at $49 \%$ [14]. Unmet need for family planning is highest in the poorest wealth quintile, at $39 \%$, and lowest in the richest wealth quintile, at $23 \%$. Important to note is that the percentage of the demand for family planning satisfied by contraceptive use is much lower in the poorest wealth quintile, at $50 \%$, compared with the richest wealth quintile, at $72 \%$ [14]

Research among rural women of reproductive age has shown that many factors significantly influence the uptake of modern family planning methods, including marital status, religion, cost of services, and proximity to care. Additionally, fear of side effects, husband's disapproval, and desire for more children are reasons for nonuse of family planning [17], [18][19]. Husbands are considered key decision-makers regarding women's health seeking and uptake of family planning [20]. Some studies have found that 
unmet need for family planning was more likely among women who had discussed family planning with their partners and whose partners disapproved of family planning [21].

Demand for family planning is considered to include women currently using modern contraception and women with unmet need for spacing and limiting births. Most of the studies done in the area of family planning focus on contraceptive use, the contraceptive methods used, and socioeconomic and demographic determinants of contraceptive use [20,22]. Studies of demand for family planning tend to focus on demand by method $[23,38]$ and in the postpartum period $[24,25]$. However, little research has been done on the factors that determine demand for family planning by wealth quintile, specifically among poor women. A further analysis of DHS data for the period 1985 to 2006 that examined unmet need and demand for family planning in Uganda found that unmet need was high among the different population groups [38].

Intermediate factors that could help to explain demand for family planning are related to exposure to family planning messages, availability of health facilities, and preference factors including education, cost of services, transportation and proximity to a facility, discussion of family planning with partners and with health workers, employment status, and others [17, 22-24]. In a systematic review of how user fees influence contraceptive use in low- and middle-income countries, findings suggested that a price increase in family planning commodities affected contraceptive use among the poor [26]. In India, in a study among women who were not using family planning, a majority mentioned fear of side effects as a reason for nonuse $[27,28]$. Demand for family planning remains an intricate issue, as different population groups seem to have barriers to accessing modern contraceptive methods, particularly poor women from rural areas and underserved communities.

In Uganda, the Ministry of Health is making efforts to provide high-impact interventions meant to achieve better health outcomes through investment in an improved maternal, newborn, child, and adolescent reproductive health plan. The need to empower the population to demand and have access to family planning commodities is pertinent not only in Uganda overall, but also among many vulnerable groups within the country. There is limited evidence to show the contribution of factors influencing the demand for family planning among poor households. Most of the existing studies have separated the key concepts including the socioeconomic and demographic, and examined them independently as factors influencing unmet need or modern contraceptive use among different population groups $[17,21-23,25$, 27]. The survey reports present descriptive unmet need for the entire population with no explanatory factors for the same or demand for family planning. This study therefore seeks to examine the factors influencing demand for family planning among poor women in a resource-limited setting.

\section{Conceptual Framework for Demand for Family Planning}

The conceptual framework guided by Integrative Model of Behavioural Prediction (IMBP) model states that a persons individual attitudes towards an issue, their norms and behavioural control would predict intention which then predicts ones behaviour. Implying that the differences in beliefs among individuals is as result of effect or experience one has generated overtime that influences their attitudes, norms and 
efficacy. In this framework, we propose that the distal variables (individual) including women's age, religion, region, residence, education attainment, employment, exposure to family planning messages work through behavioural and normative beliefs, environment factors, intention to influence one's demand to family planning.

Similarly, in this study we propose that the background characteristics including the demographic and socioeconomic factors work through the intermediate variables, including health facility associated variables $[22,24,29]$, the individual preferences, and exposure to family planning messages to influence a woman's demand for family planning [30].

In conceptual framework, we propose that a woman's current age and level of education would have an influence on her need or preference (behavioral and normative beliefs and motivation) for using contraception. Educated women would be more likely to prefer fewer children given that their perceived norm for side effects would not be a deterrent for use, are able to discuss family planning with a health care provider at a health facility, and have access to health services compared with uneducated women with a preference for more than four children and living in a rural area. The intention as depicted in the individual's discussion with a health worker about family planning or being told about family tremendously influence their demand for Family planning. The model further proposes the use skills and abilities as one the key component is behavioral prediction, in this case knowledge for about contraceptives is important for utilization. In Uganda, knowledge of contraceptive methods is the country is nearly universal [39] which is an important predictor for the behavioral prediction.

\section{Methods}

\section{Data Source}

This research article is based on the Uganda Demographic and Health Surveys (UDHS) conducted in 2006, 2011, and 2016. The Demographic and Health Survey (DHS) use similar survey methodologies across different survey periods and countries making them suitable for comparison and trend analysis. These surveys, which are conducted every 5 years, provide a wealth of information on the country's socioeconomic, demographic, maternal, household, and reproductive health indicators, including use of family planning. The surveys collect information on similar variables that can compared over time. These surveys were carried out by the National Statistical Office, Uganda Bureau of Statistics, in collaboration with ICF International. During data collection, informed consent was sought from all respondents. Details on the sample selection procedures for the respective data are described in the main survey reports [14]. The data are publicly available on The DHS Program website (www.dhsprogram.com).

\section{Sample description}


The Demographic and Health Surveys are carried out using two-stage cluster sampling to generate representative samples of women age 15-49. For all the surveys, the first stage involved the selection of clusters, followed by the second stage, which included the selection of households in each cluster. During this process, stratification by urban and rural areas was taken into consideration and the samples were drawn in accordance. The weighted samples selected for the analyses were a total of 2,238 in 2006, 2,164 in 2011, and 4,370 in 2016 [14]. The study sample included only women age 15-49 who were living in households that were classified in the lowest (poorest) and second-lowest (poorer) household wealth quintiles. The selection of the sub population using the wealth quintiles is important in identifying and addressing the challenges faced by this group. To generate the wealth index, the DHS program uses a number of steps including the identifying the indicator variables, dichotomization, estimation of the indicator weights and index value and then distribution cut off points. For instance principal component analysis is used in assigning indicator weights to generate DHS wealth index [40]. A number household possessions are used in the creation of the wealth quintiles including; household radio, television, mobile phone, tables, bed, refrigerator, bicycle, car/truck, ownership of agricultural land, boat with a motor, computer, type of housing, rooms used for sleeping, cooking fuel, and ownership of animal farm among other things [14]. Details of the sample size selection are presented in Figure 2.

\section{Variables}

The outcome variable of interest was demand for family planning. Demand for family planning included women in the sample who had an unmet need for family planning and women who were currently using any method of contraception. The definition for demand for family planning was adopted from the conventional terms and description used in family planning research $[4,5,23]$, and specifically from the description of demand used in the 2016 UDHS report. This demand variable generated herein is restricted to women in a union.

This variable (demand) was coded as a binary outcome, with 1 for women with an unmet need for spacing and limiting births as well as women currently using any contraceptive method, while 0 was for any other outcome. The list of the contraceptive methods recorded in the data included condom (both male and female), IUD, pill, sterilization (both male and female), injection, diaphragm, implant, or foam/jelly, emergency contraception, Standard Days Method/ moon beads, lactational amenorrhea method (LAM), Rhythm Method, Withdrawal [14].

The independent variables used in the analysis were place of residence (that is; rural and urban), age of the respondents (age categories; 15-24, 25-39, 40-49). The were categorized with regard to the high age specific fertility rates to tease out the factors that could be key in influencing the demand for family planning especially in the respective groups with high birth rates [14,40]. Employment status (categorized as not employed, seasonal/occasional, and all year), education level (categorized as none, primary, then secondary and above), heard of family planning messages on radio (categories: yes or no), discussed family planning at the health facility (categories: yes or no), and religion (Catholic, Anglican, 
Moslem, Other including Orthodox, Seventh Day Adventist, and Pentecostal religions). Region was categorized as central, western, southern, and northern to suit the traditional major classification of regions in Uganda, and was included in the descriptive and bivariate analyses.

\section{Data Analysis}

Descriptive analyses were done for all the selected explanatory variables including demand for family planning, and socioeconomic, demographic, and behavioral characteristics. This was followed by unadjusted logistic regression for the respective variables. Analysis at the bivariate level examined associations between demand for family planning and the explanatory variables. Finally, adjusted logistic regression models were used at the multivariate level to provide the the log-odds of demand for family planning among poor women in Uganda while controlling for the selected background characteristics. The estimated odds ratios for the respective explanatory (independent) variables were based on the $95 \%$ confidence intervals and presented in the respective models. Lastly, pooled data analyses were done to examine the most important determinants of demand for family planning overall. In the analysis of the pooled data, we incorporated the fixed effects for each DHS year.

To account for the complexities in sample survey design, all data were weighted and the survey design was taken into consideration before conducting the statistical analysis. We used the svy command in STATA in regression analyses. Further, all variables were also checked for multicollinearity before inclusion in the final models for analysis. Diagnostic tests for goodness-of-fit were done for all the logistic regression model done. A STATA command linktest was used for the for the goodness of fit test of the models given that it can be used to identify any specification error. All the analyses were executed in STATA software version 15.

\section{Results}

Table 1 presents selected background characteristics for women in union age 15-49 living in households classified in the lowest and second lowest wealth quintiles (poor women). Overall, 9 out of 10 women in all three surveys were residing in rural areas, at $98 \%$ in 2006 and in 2011, and $93 \%$ in 2016. Half of the women were age $25-39$, at $50 \%$ in 2006, 53\% in 2011, and 50\% in 2016 .

As Table 1 shows, the majority of poor women had attained primary education, and there is an observed increase over the survey years, from 68\% in 2006 to 70\% in 2011, with the highest percentage in 2016, at $72 \%$.

Table 1 Percentage distribution of poor women by selected characteristics, UDHS 2006-2016 


\begin{tabular}{|c|c|c|c|}
\hline & 2006 & 2011 & 2016 \\
\hline $\begin{array}{l}\text { Background } \\
\text { characteristics }\end{array}$ & $\begin{array}{l}\text { Frequency } \\
(n=2,239)\end{array}$ & $\begin{array}{l}\text { Frequency } \\
(\mathrm{n}=2,164)\end{array}$ & $\begin{array}{r}\text { Frequency } \\
(n=4,370)\end{array}$ \\
\hline \multicolumn{4}{|c|}{ Demand for family planning } \\
\hline No & $988(44.1)$ & $866(40.0)$ & 1,526 (34.9) \\
\hline Yes & $1,251(55.9)$ & $1,298(60.0)$ & $2,845(65.1)$ \\
\hline \multicolumn{4}{|l|}{ Place of residence } \\
\hline Urban & $50(2.2)$ & $34(1.6)$ & $303(6.9)$ \\
\hline Rural & $2,189(97.8)$ & $2,129(98.4)$ & $4,067(93.1)$ \\
\hline \multicolumn{4}{|l|}{ Age } \\
\hline $15-24$ & $718(32.0)$ & $674(31.1)$ & $1,491(34.0)$ \\
\hline $25-39$ & $1,141(51.0)$ & $1,149(53.1)$ & $2,182(50.0)$ \\
\hline $40-49$ & $380(17.0)$ & $341(15.8)$ & $697(16.0)$ \\
\hline \multicolumn{4}{|c|}{ Educational level attained } \\
\hline None & 798 (35.7) & $561(25.9)$ & $813(18.6)$ \\
\hline Primary & $1,365(61.0)$ & $1,473(68.1)$ & $3,131(71.6)$ \\
\hline Secondary and above & $75(3.4)$ & $130(6.0)$ & $427(9.8)$ \\
\hline \multicolumn{4}{|l|}{ Religion } \\
\hline Anglican & $1,183(52.9)$ & $1,086(50.2)$ & $1,275(29.2)$ \\
\hline Catholic & $695(31.0)$ & $593(27.4)$ & $2,063(47.1)$ \\
\hline Muslim & $139(6.2)$ & $171(7.9)$ & $437(10.0)$ \\
\hline Other & $220(9.9)$ & $315(14.5)$ & 597 (13.7) \\
\hline \multicolumn{4}{|l|}{ Employment status } \\
\hline Not employed & $65(2.9)$ & $435(20.1)$ & $580(13.3)$ \\
\hline Seasonal/occasional & $1,397(62.6)$ & $905(41.8)$ & $1,841(42.1)$ \\
\hline All year & 771 (34.5) & $824(38.1)$ & $1,949(44.6)$ \\
\hline \multicolumn{4}{|c|}{ Discussed family planning at health facility } \\
\hline No & $1,898(84.8)$ & $1,598(74.1)$ & $2,673(61.1)$ \\
\hline Yes & $341(15.2)$ & $560(25.9)$ & $1,698(38.9)$ \\
\hline \multicolumn{4}{|c|}{ Heard of family planning on radio } \\
\hline No & $1,231(55.0)$ & $825(38.1)$ & $1,861(42.6)$ \\
\hline Yes & $1,008(45.0)$ & 1,338 (61.9) & $2,509(57.4)$ \\
\hline \multicolumn{4}{|l|}{ Region } \\
\hline Central & $165(7.3)$ & $201(9.3)$ & $346(7.9)$ \\
\hline Eastern & 661 (29.5) & $715(33.0)$ & $1,468(33.6)$ \\
\hline Northern & 961 (42.9) & $783(36.2)$ & $1,660(38.0)$ \\
\hline Western & $453(20.3)$ & $464(21.5)$ & $896(20.5)$ \\
\hline
\end{tabular}

Table 1 further shows that $53 \%$ of respondents in 2006 and $50 \%$ in 2011 were Anglicans compared with $31 \%$ in 2006 and $27 \%$ in 2011 for Catholics. In 2016, however, $47 \%$ of respondents were Catholics compared with $29 \%$ for Anglicans. In $2006,63 \%$ of respondents were employed in seasonal or occasional activities versus $34 \%$ employed all year. In $2016,45 \%$ were employed all year and $42 \%$ were employed on a seasonal or occasional basis.

Regarding family planning seeking behavior and practices, there was a twofold increase across the surveys among women who reported that they discussed family planning at the health facility, from $15 \%$ in 2006 to $26 \%$ in 2011 , and $39 \%$ in 2016 . Over the survey years, the proportion of poor women who said they heard of family planning on radio was $45 \%$ in $2006,62 \%$ in 2011 , and $57 \%$ in 2016 . 
Examination of the demand for family planning, the key variable in this analysis, shows a notable increase in the demand for family planning among poor women over the survey years, with an observed increase in the odds ratio from 1.2 in the 2011 UDHS to 1.5 in 2016, compared with the 2006 UDHS (Figure 3).

\section{Association between Demand for Family Planning and Selected Predictors Based on the Unadjusted Regression Models}

Results of the bivariate analysis in Table 2 show a list of variables and their corresponding unadjusted odds ratios in relation to demand for family planning among poor women. The following two variables were found to have a significant likelihood of higher demand for family planning when considered independently $(O R>1)$ in all three surveys: being age 25-39 compared with age 15-24; and having attained primary education or more compared with no educational attainment.

Several other variables were found to be significant in two of the surveys: being employed all year compared with not employed (in 2011 and 2016); being Catholic compared with Anglican (in 2006 and 2011); having heard of family planning on radio compared with not having heard (in 2006 and 2011); and residence in the Eastern region compared with the Central region (in 2011 and 2016).

Table 2 Results of bivariate logistic regression analysis for demand for family planning among poor women, UDHS 2006-2016 


\begin{tabular}{|c|c|c|c|c|c|c|}
\hline \multirow[b]{2}{*}{ Variables } & \multicolumn{2}{|c|}{2006} & \multicolumn{2}{|c|}{2011} & \multicolumn{2}{|c|}{2016} \\
\hline & OR & CI & OR & CI & OR & CI \\
\hline \multicolumn{7}{|l|}{ Place of residence } \\
\hline Urban (Rc) & 1.0 & & 1.0 & & 1.0 & \\
\hline Rural & 0.9 & $0.2-3.6$ & $0.5 * *$ & $0.3-0.9$ & 1.4 & $0.9-2.2$ \\
\hline \multicolumn{7}{|l|}{ Age } \\
\hline $15-24(\mathrm{Rc})$ & 1.0 & & 1.0 & & 1.0 & \\
\hline $25-39$ & $1.4^{* *}$ & $1.2-1.7$ & $1.9^{* * *}$ & $1.5-2.4$ & $1.5^{* * *}$ & $1.3-1.8$ \\
\hline $40-49$ & 0.9 & $0.7-1.2$ & 1.2 & $0.9-1.6$ & 1.1 & $0.9-1.4$ \\
\hline \multicolumn{7}{|c|}{ Educational level attained } \\
\hline None (Rc) & 1.0 & & 1.0 & & 1.0 & \\
\hline Primary & $1.4 * *$ & $1.1-1.7$ & $1.7 * * *$ & $1.3-2.2$ & $1.7 * * *$ & $1.4-2.1$ \\
\hline Secondary and above & $2.3^{* *}$ & $1.3-3.9$ & $2.0 * *$ & $1.2-3.3$ & 2.0 *** & $1.5-2.7$ \\
\hline \multicolumn{7}{|l|}{ Religion } \\
\hline Anglican (Rc) & 1.0 & & 1.0 & & 1.0 & \\
\hline Catholic & $1.4^{* *}$ & $1.1-1.7$ & $1.5^{* * *}$ & $1.2-2.0$ & 0.9 & $0.7-1.0$ \\
\hline Muslim & 1.4 & $0.9-2.0$ & 0.9 & $0.6-1.4$ & 1.0 & $0.8-1.3$ \\
\hline Other & 1.1 & $0.8-1.6$ & $1.4^{*}$ & $1.0-1.9$ & 1.1 & $0.9-1.3$ \\
\hline \multicolumn{7}{|l|}{ Employment status } \\
\hline Not employed (Rc) & 1.0 & & 1.0 & & 1.0 & \\
\hline Seasonal/occasional & 0.8 & $0.5-1.4$ & 0.9 & $0.7-1.2$ & 1.1 & $0.9-1.4$ \\
\hline All year & 1.1 & $0.6-1.8$ & $1.4 * *$ & $1.0-1.9$ & $1.2 * *$ & $1.0-1.5$ \\
\hline \multicolumn{7}{|c|}{ Discussed family planning at health facility } \\
\hline No(Rc) & 1.0 & & 1.0 & & 1.0 & \\
\hline Yes & 1.8 & $1.4-2.4$ & 1.2 & $0.8-1.5$ & 51.0 & $0.9-1.2$ \\
\hline \multicolumn{7}{|c|}{ Heard of family planning on radio } \\
\hline No(Rc) & 1.0 & & 1.0 & & 1.0 & \\
\hline Yes & $1.8^{* * *}$ & $0.9-1.4$ & $1.5^{* * *}$ & $=1.2-1$. & 1.1 & $1.0-1.3$ \\
\hline \multicolumn{7}{|l|}{ Region } \\
\hline Central (Rc) & 1.0 & & 1.0 & & 1.0 & \\
\hline Eastern & 0.7 & $0.5-1.1$ & $1.4^{*}$ & $1.0-2.1$ & $1.3^{*}$ & $1.0-1.8$ \\
\hline Northern & 0.6 & $0.4-0.8$ & 0.8 & $0.6-1.2$ & 0.9 & $0.7-1.2$ \\
\hline Western & 0.6 & $0.4-1.0$ & 1.3 & $0.8-1.9$ & 0.9 & $0.6-1.2$ \\
\hline
\end{tabular}

\section{Rc: reference category $\quad{ }^{*} \mathrm{p}<0.10, * * \mathrm{p}<0.05, * * * \mathrm{p}<0.01$}

Table 2 shows that rural residence compared with urban residence was significant in explaining lower demand for family planning among poor women only in the 2011 survey. All variables found to be associated with demand for family planning were later tested for confounding and then examined using adjusted regression models. Region was excluded in the final adjusted regression models as it was affecting the overall results. This was only limited to the unadjusted results and there was some confounding with religion.

\section{Predictors of Demand for Family Planning among Poor Women in Uganda}

Table 3 presents the adjusted logistic regression of demand for family planning among poor women, controlling for selected predictor variables, based on data from the three UDHS surveys, 2006-2016. Three models were developed based on each of the three surveys. After controlling for possible confounding, six variables were found to be significant in association with demand for family planning: place of 
residence; age; religion; education; exposure to family planning messages on radio; and discussion of family planning at a health facility.

Table 3 Logistic regression models predicting the log-odds of demand for family planning among poor women controlling for selected variables (adjusted oddsratios are presented), UDHS 2006-2016

\begin{tabular}{|c|c|c|c|c|c|c|c|c|}
\hline \multirow[b]{2}{*}{ Variable/category } & \multicolumn{2}{|c|}{2006} & \multicolumn{2}{|c|}{2011} & \multicolumn{2}{|c|}{2016} & \multicolumn{2}{|c|}{ Pooled results } \\
\hline & $\begin{array}{l}\text { Odds } \\
\text { ratio }\end{array}$ & $95 \% \mathrm{CI}$ & $\begin{array}{l}\text { Odds } \\
\text { ratio }\end{array}$ & $95 \% \mathrm{CI}$ & $\begin{array}{l}\text { Odds } \\
\text { ratio }\end{array}$ & $95 \% \mathrm{CI}$ & $\begin{array}{l}\text { Odds } \\
\text { ratio }\end{array}$ & $95 \% \mathrm{CI}$ \\
\hline \multicolumn{9}{|l|}{ Residence } \\
\hline Urban (Rc) & 1.0 & & 1.0 & & 1.0 & & 1.0 & \\
\hline Rural & 0.9 & $\begin{array}{l}{[0.3-} \\
2.9]\end{array}$ & $0.5^{* *}$ & $\begin{array}{r}{[0.3-} \\
0.9]\end{array}$ & 1.3 & $\begin{array}{l}{[0.9-} \\
2.0]\end{array}$ & 1.1 & $\begin{array}{r}{[0.8-} \\
1.6]\end{array}$ \\
\hline \multicolumn{9}{|l|}{ Age } \\
\hline $15-24(\mathrm{Rc})$ & 1.0 & & 1.0 & & 1.0 & & 1.0 & \\
\hline $25-39$ & $1.5^{* * *}$ & $\begin{array}{l}{[1.2-} \\
1.9]\end{array}$ & $2.2^{* * *}$ & $\begin{array}{l}{[1.7-} \\
2.7]\end{array}$ & $1.7^{* * *}$ & $\begin{array}{l}{[1.5-} \\
2.0]\end{array}$ & $1.8^{* * *}$ & $\begin{array}{l}{[1.6-} \\
2.0]\end{array}$ \\
\hline $40-49$ & 1.1 & $\begin{array}{l}{[0.8-} \\
1.5]\end{array}$ & $1.5^{* *}$ & $\begin{array}{l}{[1.1-} \\
2.1]\end{array}$ & $1.4^{* *}$ & $\begin{array}{l}{[1.1-} \\
1.7]\end{array}$ & $1.3^{* * *}$ & $\begin{array}{r}{[1.1-} \\
1.6]\end{array}$ \\
\hline \multicolumn{9}{|l|}{ Educational level attained } \\
\hline Secondary + (Rc) & 1.0 & & 1.0 & & 1.0 & & 1.0 & \\
\hline None & $0.5^{* *}$ & $\begin{array}{r}{[0.3-} \\
0.8]\end{array}$ & $0.5^{* *}$ & $\begin{array}{r}{[0.3-} \\
0.8]\end{array}$ & $0.4^{* *}$ & $\begin{array}{r}{[0.3-} \\
0.6]\end{array}$ & $0.4^{* * *}$ & $\begin{array}{r}{[0.3-} \\
0.6]\end{array}$ \\
\hline Primary & 0.6 & $\begin{array}{r}{[0.4-} \\
1.1]\end{array}$ & 0.8 & $\begin{array}{c}{[0.5-} \\
1.3]\end{array}$ & 0.8 & $\begin{array}{r}{[0.6-} \\
1.1]\end{array}$ & 0.8 & $\begin{array}{l}{[0.6-} \\
1.0]\end{array}$ \\
\hline \multicolumn{9}{|l|}{ Religion } \\
\hline Anglican (Rc) & 1.0 & & 1.0 & & 1.0 & & 1.0 & \\
\hline Catholic & $1.3^{* *}$ & $\begin{array}{l}{[1.0-} \\
1.6]\end{array}$ & $1.4^{* *}$ & $\begin{array}{l}{[1.1-} \\
1.8]\end{array}$ & 0.0 & $\begin{array}{l}{[0.7-} \\
1.1]\end{array}$ & $1.1^{*}$ & $\begin{array}{l}{[1.0-} \\
1.3]\end{array}$ \\
\hline Muslim & 1.3 & $\begin{array}{l}{[0.9-} \\
1.9]\end{array}$ & 1.0 & $\begin{array}{l}{[0.6-} \\
1.5]\end{array}$ & 1.1 & $\begin{array}{l}{[0.8-} \\
1.4]\end{array}$ & 1.1 & $\begin{array}{l}{[0.9-} \\
1.4]\end{array}$ \\
\hline Other & 1.0 & $\begin{array}{l}{[0.7-} \\
1.5]\end{array}$ & 1.3 & $\begin{array}{r}{[0.9-} \\
1.8]\end{array}$ & 1.1 & $\begin{array}{r}{[0.9-} \\
1.4]\end{array}$ & $1.2 * *$ & $\begin{array}{l}{[1.0-} \\
1.4]\end{array}$ \\
\hline \multicolumn{9}{|l|}{ Employment } \\
\hline Not employed (Rc) & 1.0 & & 1.0 & & 1.0 & & 1.0 & \\
\hline Seasonal/occasional & 0.8 & $\begin{array}{l}{[0.5-} \\
1.4]\end{array}$ & 0.9 & $\begin{array}{l}{[0.7-} \\
1.2]\end{array}$ & 1.0 & $\begin{array}{l}{[0.8-} \\
1.3]\end{array}$ & 0.9 & $\begin{array}{l}{[0.8-} \\
1.1]\end{array}$ \\
\hline All year & 1.0 & $\begin{array}{l}{[0.6-} \\
1.7]\end{array}$ & 1.2 & $\begin{array}{l}{[0.9-} \\
1.7]\end{array}$ & 1.1 & $\begin{array}{c}{[0.9-} \\
1.3]\end{array}$ & $1.1^{*}$ & $\begin{array}{l}{[1.0-} \\
1.3]\end{array}$ \\
\hline \multicolumn{9}{|l|}{$\begin{array}{l}\text { Heard of family planning on } \\
\text { radio }\end{array}$} \\
\hline No (Rc) & 1.0 & & 1.0 & & 1.0 & & 1.0 & \\
\hline Yes & 1.0 & $\begin{array}{r}{[0.8-} \\
1.2]\end{array}$ & $1.4^{* *}$ & $\begin{array}{l}{[1.1-} \\
1.7]\end{array}$ & 1.1 & $\begin{array}{c}{[0.9-} \\
1.2]\end{array}$ & $1.1^{* *}$ & $\begin{array}{r}{[1.0-} \\
1.2]\end{array}$ \\
\hline \multicolumn{9}{|l|}{$\begin{array}{l}\text { Told of family planning at } \\
\text { health facility }\end{array}$} \\
\hline No (Rc) & 1.0 & & 1.0 & & 1.0 & & 1.0 & \\
\hline Yes & $1.7^{* * *}$ & $\begin{array}{l}{[1.3-} \\
2.3]\end{array}$ & 1.1 & $\begin{array}{r}{[0.8-} \\
1.5]\end{array}$ & 1.0 & $\begin{array}{c}{[0.9-} \\
1.2]\end{array}$ & $1.2^{* *}$ & $\begin{array}{l}{[1.0-} \\
1.3]\end{array}$ \\
\hline
\end{tabular}

Rc: reference category $\quad * \mathrm{p}<0.10, * * \mathrm{p}<0.05, * * * \mathrm{p}<0.01$ 
Two factors were consistent in their association with demand for family planning in all three surveys: no educational attainment (compared with secondary or more); and age 25-39 (compared with age 15-24). Women age 25-39 were twice as likely to have demand for family planning compared with women age 15-24. Similarly, in two surveys, 2011 and 2016, women age 40-49 had higher odds of demand for family planning $(A O R=1.5,95 \% \mathrm{Cl}=1.1-2.1$ in $2011 ; \mathrm{AOR}=1.4,95 \% \mathrm{Cl}=1.1-1.7$ in 2016) compared with women age 15-24. 
Women with no education had significantly lower odds of demand for family planning (AOR $=0.5,95 \%$ $\mathrm{Cl}=0.3-0.8$ in 2006; $\mathrm{AOR}=0.5,95 \% \mathrm{Cl}=0.3-0.8$ in 2011; and $\mathrm{AOR}=0.4,95 \% \mathrm{Cl}=0.3-0.6$ in 2016), compared with women with secondary education. There were also significantly increased odds of demand for family planning among Catholic women in 2006 (AOR=1.3, 95\% Cl=1.0-1.6) and 2011 AOR=1.4, 95\% $\mathrm{Cl}=1.1-1.8)$ compared with Anglican women.

Some factors were significant only in one of the surveys. In the 2011 survey, rural women had lower odds of demand for family planning ( $\mathrm{AOR}=0.5,95 \% \mathrm{Cl}=0.3-0.9)$ compared with urban women. Also in the 2011 survey, women who had heard of family planning on radio had higher odds of demand for family planning (AOR=0.4, 95\% Cl=1.1-1.7) compared with women who did not. In the 2006 survey, women who were told about family planning at a health facility had almost twice the odds of demand for family planning compared with women did not received any information ( $\mathrm{AOR}=1.7,95 \% \mathrm{Cl}=1.3-2.3$ ).

Overall, results from the pooled data showed that among poor women in the sample age, education, religion, employment status, having heard about family planning on radio and having been told of family planning at a health facility were key predictors for demand for family planning. Specifically, there were higher odds of demand for family planning among women age 25 and older compared with age 15-24, Catholic women and women in the Other category compared with Anglican women, women employed all year compared with those not employed, women who had heard of family planning on radio compared with those who had not, and women who were told of family planning at the health facility compared with those who were not. Women with no education had lower odds of demand for family planning compared with women with at least a secondary education.

\section{Discussion}

This study of demand for family planning among poor women in Uganda shows an apparent increase in demand for family planning from 2006 to 2016. In all most all the respective surveys, women's education level attained and age were key factors influencing the demand for family planning. These findings provide evidence for understanding the dynamics of contraceptive use and could be used for designing policy and program interventions for poor women in limited-resource settings [10, 18, 28]. Specifically for Uganda, this is a good entry point for the Ministry of Health and Education, whose strategic plan is to have cost-effective targeted interventions for the hard-to-reach populations [30, 31].

Meeting all of the demand for family planning in Uganda would increase the country's contraceptive prevalence from $39 \%$ to $67 \%$ [14]. Increased use of family planning has accrued benefits, as it would help mothers to space or limit births, avoid unplanned pregnancies, and reduce neonatal and maternal morbidity and mortality due to pregnancy-related complications $[2,3,14]$.

Elsewhere, women's level of education attained has been found to have an influence on uptake of modern contraceptive use generally, with a number of research studies demonstrating this linkage [24, 32, 33]. Given the benefits of education, it is likely that women who are highly educated would be more likely to demand or wish to have contraceptives compared with women who are not educated [22,32]. 
This study is one of the few to show the demand for family planning among poor rural women. Related studies, however, have extensively presented the demand satisfied [23][31], but with little evidence for those whose demand for family planning has not been satisfied. Sedgh et al. [29] presented some of the reasons for nonuse among women with an unmet need for family planning, but was not conclusive.

Our study found that in the 2011 survey, poor women who had heard family planning messages on radio had higher odds of demand for family planning compared with those who had not, while this factor was not significant in 2016. It is probable that over the 5 years between surveys more information has been disseminated, demystifying the misconceptions and perceived fears associated with use of contraception.

Women who discussed family planning at the health facility were more likely to have demand for family planning compared to those who had not, but only in the 2006 survey. It is probable that in the years since 2006 this population group has been exposed to or been informed about the side effects and other related fears about contraceptives, and therefore were better able to make decisions to either use or not use family planning, regardless of discussion with health providers [18,34]. This could also mean that in 2006 discussion with a health worker was more effective, while in the recent surveys it made no difference. Perhaps the quality of the discussion decreased and interventions could be made to create increased demand for family planning and reduce unmet need. The increased demand for family planning could also relate to the fact that such women are aware of the side effects and benefits, have used contraceptives before and found the side effects bearable, and therefore are ready to continue receiving family planning services.

Religion was found to have an impact on women's use of contraceptives. Catholics in particular are known to promote only traditional methods of family planning, including safe days and withdrawal. In our study we found that Catholic women had higher odds of demand for family planning in the 2006 and 2011 surveys. In Ghana, religious affiliation was associated with increased use of family planning [35], while in Nigeria, religion was a great influence on men's opinion regarding family planning decisions [36]. Among men in Ethiopia, religion was not an important factor considered as a determinant for contraceptive use [37].

The analysis in this study is based on cross-sectional individual data, and therefore cannot establish causality or measure the effects of certain interventions on the demand for family planning. In addition, it is limited to self-reported information from respondents, which is characteristic of cross-sectional studies. As a result, there could be respondent bias typical of cross-sectional studies whose data is generated from self-reported information. Despite these possible limitations, this study used the most appropriate statistical analytical rigor in the selection and analysis of the data. The procedures used in the data collection are rigorous as demonstrated in the survey design and sample selection procedures, ensuring quality data. Therefore, the findings of this study can be generalized among the poor women in union in Uganda. 


\section{Conclusions}

This study contributes to the discussion on provision of reproductive services to women in a resourcelimited setting. The findings show that, in at least one UDHS survey conducted in 2006, 2011, and 2016, among women in the two poorest household wealth quintiles, demand for family planning was influenced by level of education attained, discussion of family planning at the health facility, exposure to family planning messages on radio, age of the woman, and religion.

The study underscores the need to provide customized messages to the general population to negate fears associated with use of family planning, especially among the poor, uneducated, and rural women age 25 and older. The messages should easily communicate with and provide meaning to the intended population. More family planning programs need to target uneducated poor women who mainly reside in rural areas. Increased counseling by health workers on family planning methods and other services to address the perceptions and attitudes of potential clients are much needed in order to increase demand for family planning. Targeted interventions for the older and younger women need to be scaled up to provide services, but most importantly to help women appreciate the risk of conceiving in their respective age groups. Further, there is need for the health ministries to generate strategies aimed at increasing and meeting the demand generated, especially in low-income countries.

\section{Abbreviations}

AOR: Adjusted odds ratios; Cl: Confidence interval; DHS: Demographic Health Survey; IMBP: Integrative Model of Behavioural Prediction; MCH: Maternal and Child Health; OR: odds ratios; RHD: Reproductive Health Division; UDHS: Uganda Demographic Health Survey; USAID: United States Agency for International Development.

\section{Declarations}

\section{Acknowledgements}

The authors acknowledge the guidance, support, and reviews received from Dr. Ann Mwangi, Dr. Jupiter Simbeye, and Ms. Julia Fleuret during the manuscript writing process. The authors extend their gratitude to ICF for providing technical assistance through The DHS Program, a USAID-funded project providing support and technical assistance in the implementation of population and health surveys in countries worldwide. Special thanks to Dr. Shireen Assaf for the technical reviews and to Bryant Robey for copyediting this manuscript.

\section{Availability of data and materials}

The data used in the analysis of this study are all available in public domain found at http://www.dhsprogram.com/data/available-datasets.cfm. We used the UGIR70FL, which is individual Recode with data on women with completed interviews in Uganda for the 2016 DHS. 


\section{Ethics declarations}

\section{Ethical approval and consent to participate}

Permission to us the UDHS datasets was sought from the DHS program website https://www.dhsprogram.com/data/available-datasets.cfm. The Demographic and Health Survey (DHS) program ensures that all data is anonymized before it is availed to the public for access. Prior to the Demographic and Health Surveys the ICF Institutional Review Board (IRB) reviewed and approved the 2016 UDHS. The ORC MACRO, ICF Macro, and ICF IRBs complied with the United States Department of Health and Human Services regulations for the protection of human research subjects (45 CFR 46). Before the any interview was carried, all participants were required to provide informed verbal consent in order to participate in the study. The 2016 UDHS report provides all details regarding how the study was conducted.

\section{Funding}

This is study part of the further DHS analysis and manuscript writing workshop. This writing and reanalysis was done with support from the United States Agency for International Development (USAID) through The DHS Program (\#AID-OAA-C-13-00095). The views expressed are those of the authors and do not necessarily reflect the views of USAID or the United States Government.

\section{Competing interests}

The authors of this manuscript declare not conflicting interests.

\section{Consent for publication}

Not Applicable

\section{Author contribution}

AK, led the study conceptualization, reviewing literature and led the data analysis writing of the manuscript, provided the scientific rigor and reviewed the manuscript. PK participated in the conceptualization of study, data analysis and writing of the results. OV participated in the conceptualization of the study and the writing of the literature review and discussion of results. All authors reviewed and approved the manuscript.

\section{Author details}

${ }^{1}$ Dr. Allen Kabagenyi has a PhD in Population Studies. She is a researcher and lecturer in the Department of Population Studies, School of Statistics and Planning, Makerere University. ${ }^{2}$ Pamela Kakande is a senior statistician at Directorate of Population and Social Statistics, Uganda Bureau of Statistics, Kampala Uganda. ${ }^{3}$ Vianney Owayezu, coordinator of Maternal and Child Health at Division of Reproductive Health of Ministry of Health, Kampala, Uganda. 


\section{References}

1. Ahmed S, Li Q, Liu L, Tsui AO. Maternal deaths averted by contraceptive use: an analysis of 172 countries. Lancet. 2012;380:111-25. doi:10.1016/S0140-6736(12)60478-4.

2. Stover J, Ross J. How Increased Contraceptive Use has Reduced Maternal Mortality. Matern Child Health J. 2010;14:687-95. doi:10.1007/s10995-009-0505-y.

3. Tsui AO, McDonald-Mosley R, Burke AE. Family Planning and the Burden of Unintended Pregnancies. Epidemiol Rev. 2010;32:152-74. doi:10.1093/epirev/mxq012.

4. WHO. Family Planning Fact Sheet No. 351. Geneva, Switzerland; 2012.

5. WHO. World Health Organization. World Health Organization. 2018. http://www.who.int/mediacentre/factsheets/fs351/en/. Accessed 3 Jan 2018.

6. Cleland J, Harbison S, Shah IH. Unmet Need for Contraception: Issues and Challenges. Stud Fam Plann. 2014;45:105-22. doi:10.1111/j.1728-4465.2014.00380.x.

7. Bongaarts J, Bruce J. The causes of unmet need for contraception and the social content of services. Stud Fam Plann. 1995;26:57-75. http://www.ncbi.nlm.nih.gov/pubmed/7618196.

8. Bradley SEK, Croft TN, Fishel JD, Westoff CF. Revising Unmet Need for Family Planning. Calverton, Maryland, USA; 2012.

9. Prata N, Fraser A, Huchko MJ, Gipson JD, Withers M, Lewis S, et al. Women's Empowerment and Family Planning: A Review of the Literature. J Biosoc Sci. 2017;49:713-43.

doi:10.1017/S0021932016000663.

10. Casterline JB, Sinding SW. Unmet Need for Family Planning in Developing Countries and Implications for Population Policy. Popul Dev Rev. 2000;26:691-723. doi:10.1111/j.17284457.2000.00691.x.

11. Frost JJ, Sonfield A, Zolna MR, Finer LB. Return on Investment: A Fuller Assessment of the Benefits and Cost Savings of the US Publicly Funded Family Planning Program. Milbank Q. 2014;92:696749. doi:10.1111/1468-0009.12080.

12. Cleland JG, Ndugwa P, Zulu EM. Family planning in sub-Saharan Africa: progress or stagnation? Bull World Health Organ. 2011;89 October 2010:137-43.

13. Schivone G, Blumenthal P. Contraception in the Developing World: Special Considerations. Semin Reprod Med. 2016;34:168-74. doi:10.1055/s-0036-1571437.

14. UBOS, ICF. Uganda Demographic and Health Survey 2016. Kampala, Uganda and Rockville, Maryland USA, Uganda: UBOS and ICF; 2018.

15. Adebowale SA, Adedini SA, Ibisomi LD, Palamuleni ME. Differential effect of wealth quintile on modern contraceptive use and fertility: evidence from Malawian women. BMC Womens Health. 2014;14:40. doi:10.1186/1472-6874-14-40.

16. Ross J. Improved Reproductive Health Equity Between the Poor and the Rich: An Analysis of Trends in 46 Low- and Middle-Income Countries. Glob Heal Sci Pract. 2015;3:419-45. doi:10.9745/GHSP-D15-00124.

Page 17/21 
17. Kabagenyi A, Ndugga P, Wandera SO, Kwagala B. Modern contraceptive use among sexually active men in Uganda: does discussion with a health worker matter? BMC Public Health. 2014;14:286. doi:10.1186/1471-2458-14-286.

18. Kabagenyi A, Reid A, Ntozi J, Atuyambe L. Socio-cultural inhibitors to use of modern contraceptive techniques in rural Uganda: a qualitative study. Pan Afr Med J. 2016;25. doi:10.11604/pamj.2016.25.78.6613.

19. Link CF. Spousal communication and contraceptive use in rural Nepal: an event history analysis. Stud Fam Plann. 2011;42:83-92. doi:10.1111/j.1728-4465.2011.00268.x.

20. Kabagenyi A, Jennings L, Reid A, Nalwadda G, Ntozi J, Atuyambe L. Barriers to male involvement in contraceptive uptake and reproductive health services: a qualitative study of men and women's perceptions in two rural districts in Uganda. Reprod Health. 2014;11:21. doi:10.1186/1742-4755-1121.

21. Letamo G, Navaneetham K. Levels, trends and reasons for unmet need for family planning among married women in Botswana: a cross-sectional study. BMJ Open. 2015;5:e006603-e006603. doi:10.1136/bmjopen-2014-006603.

22. Andi JR, Wamala R, Ocaya B, Kabagenyi A. Modern contraceptive use among women in Uganda: An analysis of trend and patterns (1995-2011). African Popul Stud. 2014;28:1009. doi:10.11564/28-0553.

23. Ewerling F, Victora CG, Raj A, Coll CVN, Hellwig F, Barros AJD. Demand for family planning satisfied with modern methods among sexually active women in low- and middle-income countries: who is lagging behind? Reprod Health. 2018;15:42. doi:10.1186/s12978-018-0483-x.

24. Rutaremwa G, Kabagenyi A, Wandera SO, Jhamba T, Akiror E, Nviiri HL. Predictors of modern contraceptive use during the postpartum period among women in Uganda: a population-based cross sectional study. BMC Public Health. 2015;15:262. doi:10.1186/s12889-015-1611-y.

25. Barber SL. Family planning advice and postpartum contraceptive use among low-income women in Mexico. Int Fam Plan Perspect. 2007;33:6-12. doi:10.1363/3300607.

26. Korachais C, Macouillard E, Meessen B. How User Fees Influence Contraception in Low and Middle Income Countries: A Systematic Review. Stud Fam Plann. 2016;47:341-56. doi:10.1111/sifp.12005.

27. New JR, Cahill N, Stover J, Gupta YP, Alkema L. Levels and trends in contraceptive prevalence, unmet need, and demand for family planning for 29 states and union territories in India: a modelling study using the Family Planning Estimation Tool. Lancet Glob Heal. 2017;5:e350-8. doi:10.1016/S2214109X(17)30033-5.

28. Raj A, McDougal L. Leaving no one behind: can the Family Planning Estimation Tool help? Lancet Glob Heal. 2017;5:e242-3. doi:10.1016/S2214-109X(17)30050-5.

29. Sedgh G, Hussain R. Reasons for Contraceptive Nonuse among Women Having Unmet Need for Contraception in Developing Countries. Stud Fam Plann. 2014;45:151-69. doi:10.1111/j.17284465.2014.00382.x. 
30. Choi Y, Fabic MS, Hounton S, Koroma D. Meeting demand for family planning within a generation: prospects and implications at country level. Glob Health Action. 2015;8:29734. doi:10.3402/gha.v8.29734.

31. Fabic MS, Choi Y, Bongaarts J, Darroch JE, Ross JA, Stover J, et al. Meeting demand for family planning within a generation: the post-2015 agenda. Lancet. 2015;385:1928-31. doi:10.1016/S0140-6736(14)61055-2.

32. Darroch JE, Singh S. Trends in contraceptive need and use in developing countries in 2003,2008 , and 2012: an analysis of national surveys. Lancet. 2013;381:1756-62. doi:10.1016/S01406736(13)60597-8.

33. Oluwole E, Kuyinu Y, Goodman O, Odugbemi B, Akinyinka M. Factors Influencing the Uptake of Modern Family Planning Methods among Women of Reproductive Age in A Rural Community in Lagos State. Int J Trop Dis Heal. 2016;11:1-11. doi:10.9734/IJTDH/2016/20373.

34. Campbell M, Sahin-Hodoglugil NN, Potts M. Barriers to fertility regulation: a review of the literature. Stud Fam Plann. 2006;37:87-98. doi:10.1111/j.1728-4465.2006.00088.x.

35. Doctor H V., Phillips JF, Sakeah E. The Influence of Changes in Women's Religious Affiliation on Contraceptive Use and Fertility Among the Kassena-Nankana of Northern Ghana. Stud Fam Plann. 2009;40:113-22. doi:10.1111/j.1728-4465.2009.00194.x.

36. Ijadunola MY, Abiona TC, ljadunola KT, Afolabi OT, Esimai OA, OlaOlorun FM. Male involvement in family planning decision making in Ile-Ife, Osun State, Nigeria. Afr J Reprod Health. 2010;14 4 Spec no.:43-50. http://www.ncbi.nlm.nih.gov/pubmed/21812197.

37. Shaweno, T., Kura, Z. Determinants of modern contraceptive use among sexually active men in Ethiopia; using EDHS 2016 national survey. Contracept Reprod Med 5, 5 (2020). https://doi.org/10.1186/s40834-020-00108-

38. Zhang XJ, Wang GY, Shen Q, Yu YL, Sun YH, Yu GB, Zhao D, Ye DQ: Current status of contraceptive use among rural married women in Anhui Province of China. BJOG: An International Journal of Obstetrics \& Gynaecology 2009, 116(12):1640-1645.

39. Fishbein, M. (2009). An integrative model for behavioral prediction and its application to health promotion. In R. J. DiClemente, R. A. Crosby, \& M. C. Kegler (Eds.), Emerging theories in health promotion practice and research (p. 215-234). Jossey-Bass/Wiley.

40. Kabagenyi A, Reid A, Rutaremwa G., Atuyambe L., Ntozi J,. Has Uganda experienced any stalled fertility transitions? Reflecting on the last four decades (1973-2011). Fertility Research and Practice 2015, 1(4).

41. Rutstein, Shea O. and Kiersten Johnson. 2004. The DHS Wealth Index. DHS Comparative Reports No. 6. Calverton, Maryland: ORC Macro.

\section{Figures}




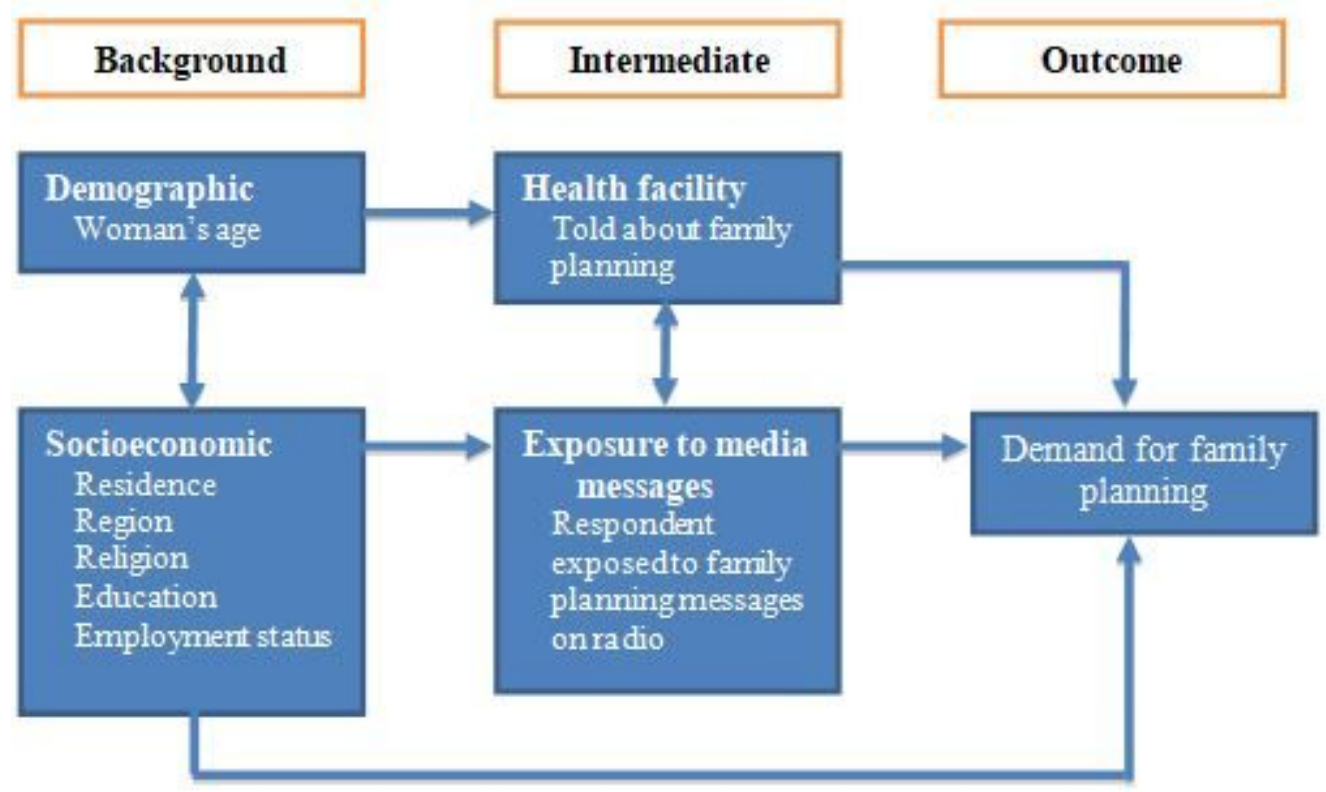

\section{Figure 1}

Conceptual framework of demand for family planning
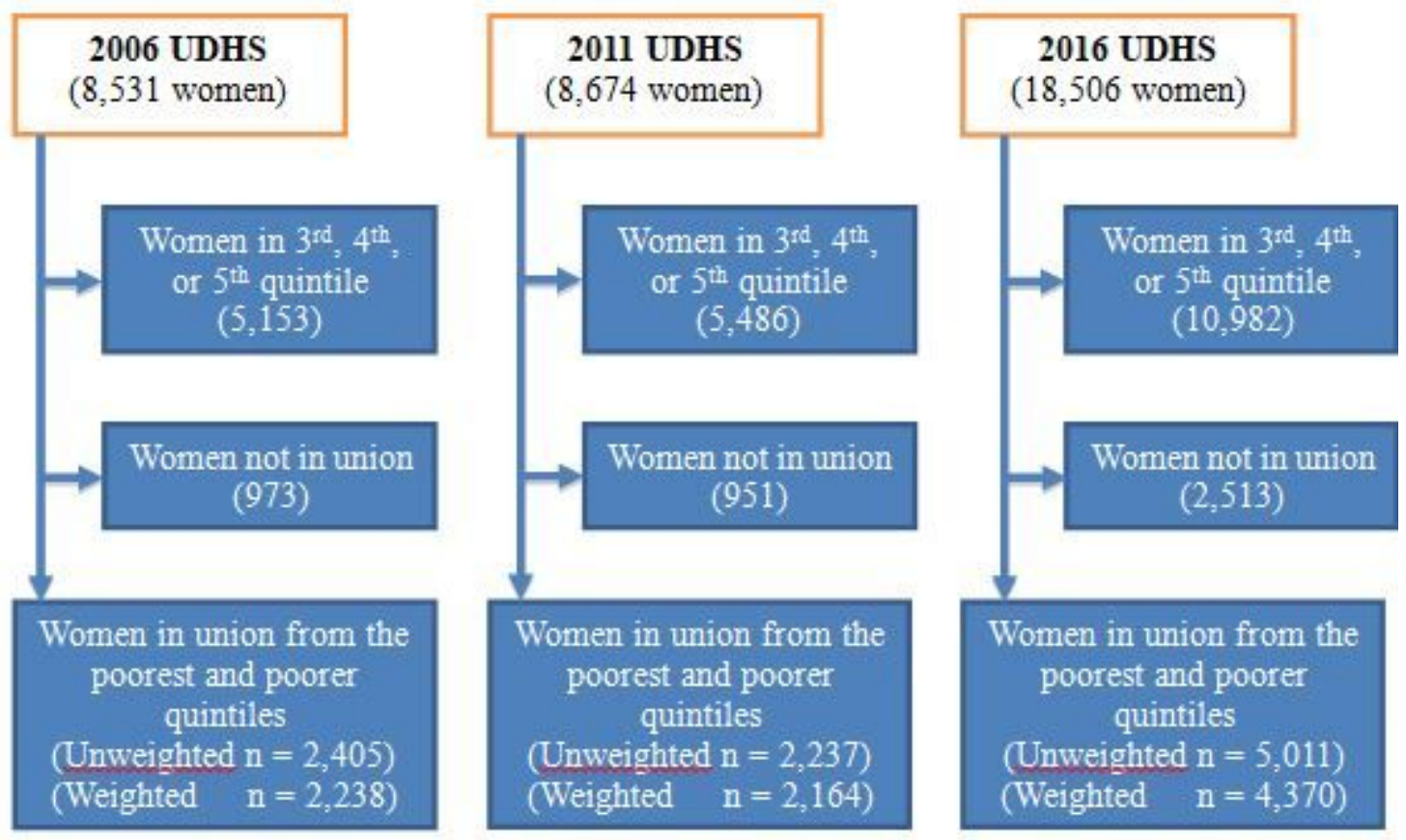

\section{Figure 2}

Derivation of weighted sample for the study period 2006-2016 adopted in the analysis of demand for family planning in Uganda 


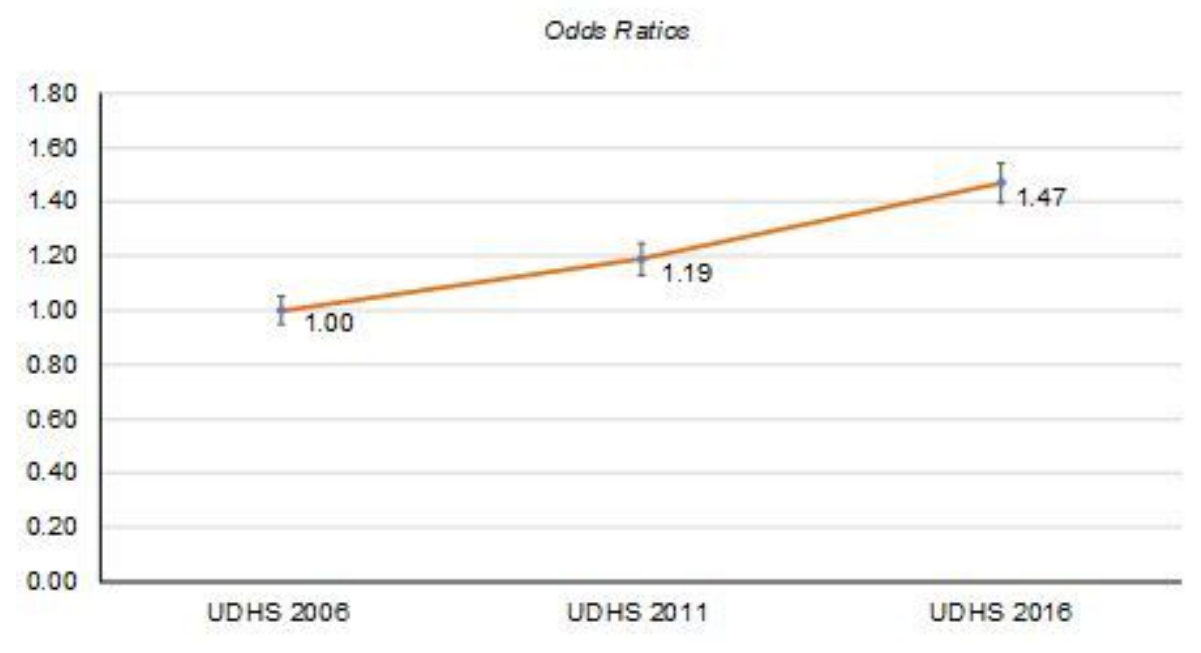

\section{Figure 3}

The odds for family planning demand among poor women age 15-49, UDHS 2006-2016 